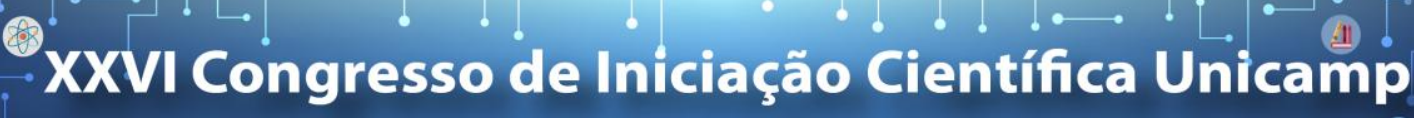

\section{CORRELAÇÃO ENTRE O PERFIL METABÓLICO E A COMPOSIÇÃO CORPORAL DE} MULHERES JOVENS SEDENTÁRIAS

\author{
Caio Patutti ${ }^{\star}$ Renata G. Duft, Joice Cristina dos S. Trombeta, Mara Patricia T.C. Mikahil, Claudia R. Cavaglieri.
}

\section{Resumo}

Dentre as análises utilizadas para identificar perfil metabólico, a metabolômica tem se destacado. $O$ objetivo deste estudo foi verificar a correlação entre os metabólitos encontrados e a composição corporal de mulheres jovens eutróficas. Análise metabolômica foi realizada através da ressonância magnética nuclear de $600 \mathrm{Mhz}$ (RMN). Os dados espectrais foram analisados no software Chenomx. Os metabólitos encontrados que foram correlacionados com a composição corporal foram: 3-hidroxibutirato, alanina, tirosina, valina, metilmalonato, propilenoglicol e piruvato. Através dos metabólitos encontrados, podemos observar uma perturbação no sistema energético das voluntárias, ocasionado possivelmente pelo excesso de gordura corporal e que pode levar a um quadro de resistencia à insulina.

Palavras-chave: Metabolômica, mulheres, composição corporal.

\section{Introdução}

Dentre as análises utilizadas atualmente, a metabolômica tem se destacado, pois os metabólitos podem representar a leitura do "status fisiológico" do organismo auxiliando na interpretação da relação entre os metabólitos e a criação de hipóteses (PROSSER, LARROUWY-AUMUS, CARVALHO, 2014).

Portanto, o objetivo deste estudo foi verificar a correlação entre os metabólitos encontrados e a composição corporal de mulheres jovens eutróficas.

\section{Resultados e Discussão}

Neste estudo 18 mulheres jovens (idade $30,16 \pm 5,19$ anos, altura $1,63 \pm 0,07 \mathrm{~cm}$, peso $55,82 \pm 7,72$ $\mathrm{kg}$ ) tiveram a composição corporal analisada por meio do BOD POD $\AA$, a aptidão cardiorrespiratória através de um protocolo de esforço em esteira ergométrica, com coleta contínua dos gases (Oxycon®) e amostras de sangue venoso foram coletadas após um jejum de 12 horas. Análise metabolômica foi realizada através da ressonância magnética nuclear de $600 \mathrm{Mhz}(\mathrm{RMN})$. Os dados espectrais foram analisados no software Chenomx.

Para o teste de normalidade dos dados foi utilizado o teste de Shapiro-wilk. Posteriormente as correlações entre os metabólitos encontrados e as medidas de massa magra e massa gorda foram testadas através da Correlação de Pearson e Sperman.

Tabela 1. Valores do consumo de oxigênio e de composição corporal das participantes.

\section{Média \pm D.P}

\begin{tabular}{lc}
\hline $\mathrm{VO}_{2}\left(\mathrm{ml}, \mathrm{kg}^{-1} \cdot \mathrm{min}^{-1}\right)$ & $28,23 \pm 2,8$ \\
$\%$ Massa Magra & $68,7 \pm 7,48$ \\
$\%$ gordura & $31,29 \pm 7,48$ \\
$\mathrm{IMC}\left(\mathrm{kg} / \mathrm{cm}^{2}\right)$ & $20,8 \pm 2,29$
\end{tabular}

$\mathrm{VO}_{2}$ : consumo de oxigênio; D.P: desvio padrão

O aumento da concentração dos aminoácidos (AAs) pode estar relacionado à três fatores: 1) alteração da composição corporal das voluntárias; Estudos recentes têm apontado a presença de altas concentrações de AA em indivíduos obesos (LAFERRERE et al, 2011); 2) um possível desenvolvimento de um quadro de resistência a insulina
(RI), fato apoiado pelo também aumento da concentração de 3-Hidroxibutirato (GALL et al, 2010); 3) baixo nível de aptidão cardiorrespiratória das participantes (CHORELL et al, 2012);

Tabela 2. Correlação entre os metabólitos encontrados e as variáveis da composição corporal

\begin{tabular}{ccc}
\hline Metabólitos & $\begin{array}{c}\text { Massa Gorda } \\
(\%)\end{array}$ & $\begin{array}{c}\text { Massa Magra } \\
(\%)\end{array}$ \\
\hline 3-Hidroxibutirato & $0,572^{*}$ & $-0,572^{*}$ \\
Alanina & $0,565^{*}$ & $-0,565^{*}$ \\
Glicose & $0,505^{*}$ & $-0,505^{*}$ \\
Metilmalonato & $0,627^{* *}$ & $-0,627^{* *}$ \\
Propilenoglicol & $0,777^{* *}$ & $-0,777^{* *}$ \\
Piruvato & $0,564^{*}$ & $-0,564^{*}$ \\
Tirosina & $0,542^{*}$ & $-0,542^{*}$ \\
Valina & $0,588^{*}$ & $-0,588^{*}$ \\
\hline
\end{tabular}

Coeficiente de correlação $r \quad{ }^{*} p<0.05 /{ }^{* *} p<0.01$

Também podemos observar que 0 aumento dos AAs podem estar ocasionando uma perturbação no sistema energético (CHAMPE, HARVEY, FERRIER, 2006). E por último, hipotetizamos que, a correlação positiva da glicose com a \% de gordura reforça o quadro da RI.

\section{Conclusões}

Pode-se observar uma perturbação no sistema energético, ocasionado possivelmente pelo excesso de gordura corporal e que pode levar a um quadro de resistência à insulina.

\section{Agradecimentos}

Agradeço ao PIBIC/CNPq, a FAPESP, ao Laboratório Nacional de Biociências (LnBio) e a professora Maria Cristina Marcondes do Instituto de Biologia da Unicamp.

1. Morris, et al. The relationship between aerobic fitness level and metabolic profiles in healthy adults. Mol. Nutr. Food Res. V.57, 2013.

2. PROSSER, G.A., LARROWY-MAUMUS G., CARVALHO, L.P.S Metabolomic strategies for the identification of new enzyme functions and metabolic pathways. EMBO reports, v.15(60),2014.

3. Chorell, et al. Physical fitness level is reflected by alterations in the human plasma metabolome. Molecular Biosystems, v.8, 2012.

4. Laferrere, et al. Differential metabolic impact of gastric bypass surgery versus dietary intervention in obese diabetic subjects despite identical weight loss. Sci. Transl. Med, v.3, 2011. 